\title{
Assessment Of The Excellence Of Academic Advising: Lessons Learned
}

Tahmoures Afshar, Woodbury University

Satinder Dhiman, Woodbury University

\begin{abstract}
Numerous studies have described the importance of the quality of academic advising in student retention. Some studies have explored the impact of effective academic advising on student retention rates while others have explored the correlation between student retention/satisfaction and advisor-student interaction. Recent studies have also demonstrated the range of students' expectations about academic advising. However, there are not very many studies to indicate what factors affect an advisor's effectiveness and success in their performance. Our study attempts to fill this gap in the literature by incorporating these issues in an academic advising effectiveness process. For the purpose of this study, a sample of 225 students in an urban, private university was used to assess the excellence in academic advising. We found that excellence in academic advising is greatly linked to such factors as students' personal, cultural, and academic background, including the quality of their relationship with their advisor.
\end{abstract}

\section{INTRODUCTION}

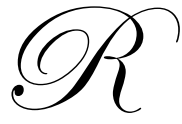

background.

ecently, there has been a significant increase in the number of students with diverse cultural background enrolling in American colleges and universities. It has also been noted that as university enrollment goes up, so does the number of students with diverse ethnicity, age, gender, and family

It has been accepted by a good number of researchers that there is a positive relationship between college student retention and effective advising. Students' expectations during advising cannot be met unless the faculty advisor is aware of the needs of the diverse student body. The most commonly stated expectation of students receiving advising services is the ability of their advisor to provide the accurate guidance in a timely manner (Creamer and Scott, 2000). However, students with different cultural, personal, and academic attributes may assess the effectiveness of their advisors quite differently. Apparently, freshman students' perception of advisor's effectiveness could be quite different than that of a senior student. Student in different schools and with different majors would also evaluate their advisors differently. Gender difference, age, GPA, class status, longevity with the current advisor, number of visits to the advisor and their duration, all these variables may call for new considerations in assessing the excellence in academic advising.

There are not very many studies that indicate what factors affect advisor's effectiveness and success in their advising process. Our present study attempts to bridge this gap in the literature by incorporating these issues in the academic advising evaluation process. We address the following questions through our study:

1. Whether or not student's personal, cultural, and academic background are important factors determining effectiveness of academic advising process?

2. Whether or not the results presented here confirm the results of previous studies?

3. Whether or not advisor's gender has any impact on students' perception regarding the excellence in academic advising? 
The last issue has not been addressed adequately in the literature and will be addressed for the first time in our study.

For the purpose of this study, 225 students in an urban, private university were asked to complete a structured questionnaire to assess the excellence in academic advising. We found that excellence in academic advising is greatly linked to such factors as students' personal, cultural, and academic background, including the quality of their relationship with their advisor.

\section{LITERATURE REVIEW}

Numerous studies have described the important role of the quality of academic advising on student's retention (Adams et al. 1990; Afshar \& O'Hara, 2005; 2006; Backhus, 1989; Burnett et al., 2003; Crockett, 1978; Crookston, 1972; Kelly et al., 1991; King, 1993; Levitz et al., 1999; Nadler and Simerly, 2006; Stevenson et al. 2006-2007; Torres, 2003). Nadler and Simerly (2006, p. 215) examined the "perceived importance of listening and the willingness of the students to both trust an academic advisor and to commit to work with that advisor." Backhus (1989) and King (1993) among others have explored the importance of effective academic advising on student retention rates. Burnett et al (2003) stated that the quality of an institution's student supporting system could make the difference between students who are enjoying a satisfying experience and those who are struggling with frustration and confusion. Studies by Astin (1993) and Light (2000) suggested that there was a positive correlation between student retention and satisfaction with advisor-student interaction. Recent studies have also demonstrated the range of expectations about advising. Fielstein (1987 and 1989) reported that students wanted an advisor who assisted students with registration process, major/minor decision making process and course selection.

Couch (2005) reports that advisors serve as facilitators who explore student needs and desires based on student's social, personal, and cultural background. Vernez and Mizell (cited in Devall et al., 2005, p. 52) state that "because inadequate academic advising is an obstacle to obtaining a bachelor's degree, faculty advisors are encouraged to develop personal relationship with their advisees." Of particular note regarding the importance of good advising in student's ultimate success towards degree completion is the commentary provided by Stevenson et al. (2006-2007). They note that student's academic failure is closely linked to lack of faculty advisement or poor faculty advisement (p. 146).

\section{METHOD}

Sample: Participants for this study were 225 students in an urban, private university who completed a structured questionnaire consisting of twenty- nine questions during fall 2005. These twenty-nine characteristics/responsibilities were those most often cited in the literature as critical for an effective academic advisor. The student was asked to provide some personal, cultural, and academic information on themselves including age, gender, ethnicity, class status, GPA, major, school. In addition, student was asked to rate their current on each question as excellent, very good, good, average, and poor.

Demographic characteristics of students are depicted in Table 1.

\section{RESULTS}

In assessing the excellence in academic advising process, we utilized following three categories. First category was student personal/cultural traits. This category consisted of student's gender, age, and ethnicity. Second category was student's academic characteristics and included student's GPA, class status, major, and school. Third category pertains to advisor's personal and attitudinal characteristics. This category consisted of number of student-advisor visit per semester, duration of each visit measured in certain minutes, number of semester(s) student was advised with current advisor, number of courses student has had with current advisor, number of advisor student has had before assigned to current advisor, and the gender of advisor. The latter variable has not been addressed in the previous research and was introduced for the first time in this study. 
First, advisor's excellence assessment and student's personal/cultural characteristics:

a)

Student gender effect:

As evidenced from Table 2, in excellent rating category, male student's rate (48\%) outnumbered female student 's rate $(42 \%)$ by margin of 6 percent. However, in other rating categories female students favor their advisors more than male students. Since there was inconsistency between "excellent" and "very good" categories we combined these two categories and renamed it as "excellence" in advising and examined it. Similarly, we combined "good" and "average" categories and renamed it as "adequate" in advising process and examined the combination instead. The last category "poor" was kept and studied it as itself. This new arrangement was shown in Table 3. For consistency purposes, we continued utilizing these created combined categories in the rest of this study.

In "excellence" category, male students rated their current advisors at $81 \%$ of popularity, which was well above female students rating at $75 \%$. One possible explanation for our result that male students favor their current advisor more favorably than female student is that female student performed better in school. As Table 1 indicated, $69 \%$ of female students have had 3.01-4 GPA versus $31 \%$ of male students. Consequently, female student's expectations for "excellence" in advising are well above male students. As a result, as shown in Table 3, female students' rating in "adequate" category was higher than male students' rating. That is, female students were not quite convinced that their advisor deserved to receive more than $75 \%$ in "excellence" category. However, male students were not quite satisfied with their current advisor performance completely because $2 \%$ of them indicated that their advisor was conducting at "poor" category.

The finding of this study vividly demonstrated that gender mattered in assessment of excellence in advising. This result confirmed the finding of Afshar and O'Hara (2006). Their study found that there was a statistically significance differences in perception of male and female students.

b) Student's age effect:

As was shown in table 3, students in 24-26 age group rated their advisor in "Excellence "category more favorably $(83 \%)$ than other age groups. Perhaps one possible explanation for this result is that older students were close to graduation and have realized the value of their current advisor's assistance more than other age groups. Younger students: 18-20 and 21-23 have had identical rating scale for their current advisor in "excellence" category. However, younger students somehow were not very satisfied with their advisor's performance. Hence, they rated the current advisor at 24\% (18-20 age group) and 20\%(21-23 age group). Older student's rating in "excellence" category was lower than other age groups. On the other hand, student at 27-29 age group, rated higher percentage for their current advisor in "adequate" category, indicating less satisfaction in receiving advising guidance than other age groups in this study. We concluded that age was an important factor in assessment of excellence in academic advising evaluation process.

c) Student ethnicity effect:

As was evidenced from Table 3, among all five ethnicity groups, Arminian Students rated their current advisor at $88 \%$ in "excellence" category followed by Asian student's $76 \%$ rating and White/American at $75 \%$. In the same category, the lowest rating for current advisor was made by African American with $63 \%$. In "adequate" category, Hispanic students rated their advisor at 30\% and African American students at $37 \%$ indicating somewhat of dissatisfaction with current advisor's effectiveness. In addition, Hispanic, Asian, and American students by rating their advisor in "poor" category reflected their advisor's failure in academic advising process. The noticeable differences among students with various ethnicity background in this study, made us to conclude that ethnicity mattered in assessing the excellence in advising evaluation process. 
Second, advisor's excellence assessment and student's academic characteristics:

a) Student's GPA effect:

As shown in Table 4, in excellence category for advisor's performance, students with a GPA higher than 3.0 highly favored their advisors. Students with a GPA of 3.0 or less than 3.0 gave a lower rating. It was interesting to find that students with 3.0+ GPA had similar perceptions in rating their advisors in adequate category and so were the students with 3.0 - GPA. However, we found that most successful students rated their advisor quite differently than students in lowest GPA group. Thus, we concluded that GPA did matter in assessing excellence in academic advising.

b) Student's class status effect:

As shown in Table 4, both the freshman and Senior students rated their advisors at the highest rate in the "excellence" category. Sophomore and Junior students' rating behavior at all 3 assessment groups was identical. In particular, both sophomore and junior students felt that at times their advisor failed to provide them with the satisfactory guidance. Hence, they rated their advisor at the "poor" category with a very low percentage. In the "poor" rating category, we felt that even small percentage indicates somewhat dissatisfaction of students in regards to the performance of their advisor. Our findings suggested that class status played a role in assessing the excellence of academic advising.

c) Student's major effect:

As shown in Table 4, students majoring in Computer Information Systems/IT and Psychology rated their advisors at $100 \%$ of excellence. Students majoring in design areas gave their advisors the lowest rating. Thus, we found that students with different majors rated the effectiveness of their advisors quite differently. This result indicated that student major indeed did matter in the assessment of advisor's excellence in academic advising.

d) Student's school effect:

Finally, in the students' academic characteristics category, we examined the role of student's school in their evaluation of advisor's effectiveness in advising. As shown in Table 4, Arts and Science students were more satisfied with their advisors and ranked their excellence at $80 \%$ followed by Business school's students with $74 \%$ rating. Students in the school of Architecture and Design had lowest percentage in excellence category and highest in both adequate and poor categories. This result confirmed that a student's school did make a difference in their assessment of their advisor's excellence in academic advising.

Third, advisor's excellence assessment and advisor's personal and attitudinal characteristics:

a)

Frequency of student's interaction/meeting with the advisor:

As shown in Table 5, the greater the frequency of student's interaction with the advisor, the higher the rating of their advisor's excellence in academic advising. Students that have had 1-3 times (fewer) visits with their advisors demonstrated more dissatisfaction with advisor in both adequate and poor rating categories. Thus, we found that the frequency of advisor's interaction with the students played a major role in assessment of excellence of academic advising.

b) Duration of advisor-student visit effect:

As presented in Table 5, the longer the time an advisor spent with the student during each and every visit, the greater the rating in excellence category and vice versa. Thus, the length of time an advisor spent with the student proved to be a determining factor in the assessment of excellence of academic advising. 
c) Number of semesters with the current advisor effect:

As shown in Table 5, except for zero semesters, the most popular response was from students who experienced advising event with their advisor for 'one or more semesters.' However, in working with the advisor for 'three or more semesters,' students started rating their advisor lower in the excellence category. Hence, the number of semesters with the current advisor is significant in assessing the excellence in academic advising.

d) Student with many different advisors effect:

As shown in Table 5, student's excellence rating of advising faded out as many advisors were experienced by the student. A student who has been with the current advisor for only one semester demonstrated the highest rating $(84 \%)$ in the evaluation process. Thus, the higher the number of advisors a student works with, the lower the satisfaction rating with the advising process.

e) Number of courses with the current advisor:

As presented in Table 5, the greater the number of courses taken with the current advisor, the better the rating results in excellence category of evaluation process. This shows that prior acquaintance of students with their current advisor has a significant effect on advisor-student relationship.

f) Gender of advisor:

As shown in Table 5, male advisors demonstrated a much better rating race than female advisors. This result revealed that an advisor's gender was a determining factor in assessing the excellence in academic advising. The interesting finding was that advisor's male-female differences at both excellence and adequate category level were the same. Thus we found that the gender of advisor mattered in the assessment of the excellence of academic advising process.

\section{CONCLUSION/DISCUSSION}

In assessment of the excellence of academic advising, we utilized a sample of 225 students who enrolled in a private university in fall 2005 . The students in this study were asked to rate their advisor with regards to twentynine questions identifying the main responsibility of a typical advisor. The student had five choices to rate their current advisor: excellent, very good, good, average, and poor. Students were asked to provide information on personal, cultural, and academic background. Data on personal/ cultural background included age, gender, and ethnicity. Academic information included GPA, class standing, major and school. In addition, students were asked to provide information on student-advisor relationship describing the following variables: number of visits with the advisor per semester, length of the visits, number of courses the student has had with the current advisor before being assigned to the current advisor. In addition, we introduced advisor gender as a new variable, which to our knowledge, has not been widely studied in this context. Our study revealed that student's personal, cultural, academic factors together with their interaction with the current advisor were the determining factors in assessing excellence in academic advising.

A number of lessons can be gleaned from this study that may help identify the characteristics of an excellent and effective academic advisor, as follows:

1. Our findings suggest that students highly rate and favor an advisor who spent 30 plus minutes in each advising session. Student's rating response was $88 \%$ in this regard. This result confirmed the findings of Afshar and O'Hara (2005).

2. Students identified excellent advisor as the one with whom they have had some previous familiarity. In our study familiarity was defined (determined) by having two courses (80\%) with the advisor and having been the advisee of the current advisor for at least one semester. 
3. Advisor gender was revealed to have positive effect on excellence in academic advising. Male advisor was preferred $81 \%$ vs. $75 \%$ female by the students.

4. Student gender was also revealed to be a determining factor in excellence in academic advising. In our study, we found that male students show greater appreciation and, consequently, higher preference for their current advisor.

5. Students enrolled in non technical schools such as Arts and Sciences show better appreciation of the advising process than students enrolled in School of Architecture and Design and School of Business. As a result, advisors in less technical schools may have a better chance to be rated higher than other schools.

6. Our study indicates that advisors who advised relatively more mature students had a better chance to be nominated as excellent advisor.

7. Students with higher GPA tended more likely to rate their current advisor as excellent than academically weak students. In our study, students with 3.01-4 GPA rated their advisor as excellent/very good with 83\% preference rate.

8. Student's ethnic background should be approached differently. Although results may vary from one institution to another, in our sample, Armenian students favored their advisors with $88 \%$ preference rate among all other students with different ethnic background.

9. Our study revealed that freshman students had a very high excellence rating for their advisors than sophomore, juniors, and seniors.

In conclusion, these lessons offer a new perspective on academic advising. These lessons may inform an advisor of several factors, variables, and traits that determine successful advising and thereby help improve his/her effectiveness in academic advising. For example, if male students ranked their current advisor much higher than female students, a discerning advisor should try to discover the reasons for lower ratings by female students and thus try to improve the advising process, gender-wise.

An effective advising benefits both students and institutions. To achieve excellence in student advising, an advisor needs to be aware of the diverse needs and expectations of diverse student population that characterize today's dynamic institutions of higher learning. The authors wish to point out that the conclusions of this study are valid within the context of the parameters of the present study. It is not our intention to generalize the results across the board.

Table 1

Demographic Characteristics of Students

\begin{tabular}{|l|c|c|c|}
\hline Characteristics & Female & Male & Total \\
\hline Gender & 140 & 82 & 222 \\
\hline Freshman (Fr) & 21 & 14 & 35 \\
\hline Sophomore (So) & 28 & 19 & 47 \\
\hline Junior (Jr) & 47 & 28 & 75 \\
\hline Senior (Sr) & 41 & 18 & 59 \\
\hline Age: $18-20$ & 73 & 28 & 111 \\
\hline $21-23$ & 46 & 30 & 76 \\
\hline $24-26$ & 10 & 15 & 25 \\
\hline $27-29$ & 5 & 7 & 12 \\
\hline $2-2.5$ & 3 & 7 & 10 \\
\hline $2.51-3$ & 21 & 23 & 44 \\
\hline $3.01-3.5$ & 45 & 19 & 64 \\
\hline $3.51-4$ & 23 & 12 & 35 \\
\hline GPA: & 18 & 14 & 32 \\
\hline Hispanic (Hi) & 49 & 16 & 65 \\
\hline Asian (As) & 29 & 22 & 51 \\
\hline American/White (AW) & 21 & 12 & 33 \\
\hline African American & 4 & 6 & 10 \\
\hline Architecture \& Design & 35 & 27 & 62 \\
\hline Arts \& Science & 36 & 13 & 49 \\
\hline
\end{tabular}


Table 2

Student's Cultural/Personal Data

Numbers in ( ) are in Percentages (relative frequency)

\begin{tabular}{|c|c|c|c|c|c|c|}
\hline \multicolumn{7}{|c|}{ Numbers in ( ) are in Percentages (relative frequency) } \\
\hline & & Excellent & Very Good & Good & Average & Poor \\
\hline \multirow[t]{2}{*}{ Gender } & Female & $56(42)$ & $44(33)$ & $22(17)$ & $11(8)$ & 0 \\
\hline & Male & $35(48)$ & $24(33)$ & $9(12)$ & $3(4)$ & $2(2)$ \\
\hline \multirow[t]{4}{*}{ Age } & $18-20$ & $41(43)$ & $33(34)$ & $21(22)$ & $2(2)$ & 0 \\
\hline & $21-23$ & $45(54)$ & $19(23)$ & $6(7)$ & $11(13)$ & $2(2)$ \\
\hline & $24-26$ & $10(44)$ & $9(39)$ & $3(13)$ & $1(4)$ & 0 \\
\hline & $27-29$ & $3(25)$ & $6(50)$ & $2(17)$ & $1(8)$ & 0 \\
\hline \multirow[t]{5}{*}{ Ethnicity } & Armenian & $20(63)$ & $8(25)$ & $3(9)$ & $1(3)$ & 0 \\
\hline & Hispanic & $23(38)$ & $18(30)$ & $13(21)$ & $6(10)$ & $1(2)$ \\
\hline & Asian & $16(42)$ & $13(34)$ & $4(11)$ & $4(11)$ & $1(2)$ \\
\hline & White/American & $12(41)$ & $10(34)$ & $2(7)$ & $4(14)$ & $1(3)$ \\
\hline & African American & $1(13)$ & $4(50)$ & $2(25)$ & $1(13)$ & 0 \\
\hline
\end{tabular}

Table 3

Student's Personal/Cultural Characteristics Numbers in ( ) are in Percentages (relative frequency)

\begin{tabular}{|c|c|c|c|c|}
\multicolumn{9}{|c}{ Numbers in ( ) are in Percentages (relative frequency) } \\
\cline { 2 - 5 } & & Excellence & Adequate & Poor \\
\hline Gender & Female & $100(75)$ & $33(25)$ & 0 \\
\hline Age & Male & $59(81)$ & $12(17)$ & $2(2)$ \\
\hline & $18-20$ & $74(77)$ & $23(24)$ & 0 \\
\hline & $21-23$ & $64(77)$ & $17(20)$ & $2(2)$ \\
\hline & $24-26$ & $19(83)$ & $4(17)$ & 0 \\
\hline & $27-29$ & $9(75)$ & $3(25)$ & 0 \\
\hline & Armenian & $28(88)$ & $4(12)$ & $1(2)$ \\
\hline & Hispanic & $41(68)$ & $19(30)$ & $1(2)$ \\
\hline
\end{tabular}

Table 4

Student's Academic Characteristics

Numbers in ( ) are in Percentages (relative frequency)

\begin{tabular}{|c|c|c|c|c|}
\hline & & & & \\
\hline & & Excellence & Adequate & Poor \\
\hline \multirow[t]{4}{*}{ GPA } & $2-2.5$ & $4(57)$ & $3(43)$ & 0 \\
\hline & $2.51-3$ & $15(56)$ & $11(41)$ & $1(4)$ \\
\hline & $3.1-3.5$ & $48(83)$ & $10(17)$ & 0 \\
\hline & $3.51-4$ & $28(82)$ & $6(18)$ & 0 \\
\hline \multirow[t]{4}{*}{ Class } & Freshman & $29(88)$ & $4(12)$ & 0 \\
\hline & Sophomore & $33(73)$ & $11(24)$ & $1(2)$ \\
\hline & Junior & $51(73)$ & $19(27)$ & $1(1)$ \\
\hline & Senior & $47(82)$ & $10(18)$ & 0 \\
\hline \multirow[t]{11}{*}{ Major } & Accounting & $12(80)$ & $3(20)$ & 0 \\
\hline & Management & $58(74)$ & $20(26)$ & 0 \\
\hline & IT & $8(100)$ & 0 & 0 \\
\hline & Marketing & $13(76)$ & $4(24)$ & 0 \\
\hline & Animation Arts & $7(88)$ & $1(12)$ & 0 \\
\hline & Architecture/Interior & $23(66)$ & $11(31)$ & $1(3)$ \\
\hline & Fashion/Graphic Design & $14(52)$ & $12(44)$ & $1(4)$ \\
\hline & Communication & $11(92)$ & $1(8)$ & 0 \\
\hline & Interdisciplinary Studies & $4(80)$ & $1(20)$ & 0 \\
\hline & Politics \& History & $7(78)$ & $2(22)$ & 0 \\
\hline & Psychology & $5(100)$ & 0 & 0 \\
\hline \multirow[t]{3}{*}{ School } & Business & $39(74)$ & $14(26)$ & 0 \\
\hline & Architecture \& Design & $10(59)$ & $6(35)$ & $1(6)$ \\
\hline & Arts \& Science & $16(80)$ & $4(20)$ & 0 \\
\hline
\end{tabular}


Table 5

Advisor's Personal Attitudinal Characteristics

Numbers in ( ) are in Percentages (relative frequency)

\begin{tabular}{|c|c|c|c|c|}
\hline & & Excellence & Adequate & Poor \\
\hline \multirow[t]{4}{*}{$\begin{array}{c}\text { Number of } \\
\text { Visit/Semester }\end{array}$} & $1-3$ Times & $70(74)$ & $23(24)$ & $2(2)$ \\
\hline & 4 - 7 Times & $55(76)$ & $17(24)$ & 0 \\
\hline & $8-11$ Times & $12(71)$ & $5(29)$ & 0 \\
\hline & 12 or more & $24(92)$ & $2(8)$ & 0 \\
\hline \multirow[t]{3}{*}{ Duration of Visit } & $10-15$ Minutes & $67(67)$ & $33(33)$ & 0 \\
\hline & $20-30$ Minutes & $71(87)$ & $11(13)$ & 0 \\
\hline & $30+$ Minutes & $23(88)$ & $3(12)$ & 0 \\
\hline \multirow[t]{4}{*}{$\begin{array}{c}\text { Number of Semester w/ } \\
\text { Current Advisor }\end{array}$} & 0 & $1(100)$ & 0 & 0 \\
\hline & 1 & $93(81)$ & $21(18)$ & $2(1)$ \\
\hline & 2 & $19(79)$ & $5(21)$ & 0 \\
\hline & $3+$ & $46(70)$ & $20(30)$ & 0 \\
\hline \multirow[t]{4}{*}{$\begin{array}{l}\text { Student with Many } \\
\text { Different Advisor }\end{array}$} & 0 & $5(100)$ & 0 & 0 \\
\hline & 1 & $76(84)$ & $14(16)$ & 0 \\
\hline & 2 & $64(72)$ & $24(27)$ & $1(1)$ \\
\hline & $3+$ & $15(60)$ & $9(36)$ & $1(4)$ \\
\hline \multirow[t]{3}{*}{$\begin{array}{c}\text { Courses with Current } \\
\text { Advisors } \\
\end{array}$} & 1 & $64(78)$ & $18(22)$ & 0 \\
\hline & 2 & $33(80)$ & $8(20)$ & 0 \\
\hline & $3+$ & $26(79)$ & $7(21)$ & 0 \\
\hline \multirow[t]{2}{*}{ Gender of Advisor } & Female & $54(75)$ & $18(25)$ & 0 \\
\hline & Male & $113(81)$ & $26(19)$ & 2 \\
\hline
\end{tabular}

\section{REFERENCES}

1. Afshar, Tahmoures and O'Hara, Leo (2006). Pedagogical Issues Concerning Academic Advising. Journal of College Teaching and Learning. 3(11), pp. 25-44.

2. Afshar, Tahmoures and O'Hara, Leo (2005). Student Perception of Academic Advising, in Proceeding of the Fifth Annual Hawaii International Conference on Business, Honolulu, Hawaii, May 26-29.

3. Astin, A.W. (1993), What Matters in College? Four Critical Years Revisited. San Francisco: Jossey-Bass Publishers.

4. Backhus, D. (1989). Centralized Intrusive Advising and Undergraduate Retention. NACADA Journal 9, pp. 39-45.

5. Burnett, D. and Oblinger, D.(2003). Student Academic Services, Current Practices and Trends. In Kranner, G.L. \& Associates (Eds), Students Academic Services. An Integrated Approach (pp. 27-52). San Francisco: Jossey-Bass Publishers.

6. Crockett, D.S. (1978). Academic Advising : A cornerstone of student retention. In Noel, L.(Ed.), New directions for student services: Reducing the dropout rate (pp.29-38). San Francisco: Jossey-Bass Publishers.

7. Couch, Renee Chaffin (2004). Trends in Sophomore Students' Perceptions of Academic Advising Services at East Tennessee State University. Doctor of Education Dissertation.

8. Creamer, D.S. (2000). Use of Theory in Academic Advising. In Gordon, V.N., Habley, W.R. and Associates, Academic Advising: A Comprehensive Handbook (pp. 18-34). San Francisco: Jossey Bass Publisher.

9. Crookston, R.B. (1972). A Developmental View of Academic Advising as Testing. Journal of College Student Personnel, 13 (1), pp. 12-17.

10. Devall, E., Vail, A., \& Resendez, J. (Nov. 2005). Strategies for Recruiting and Retaining Hispanic Students. Journal of Family and Consumer Sciences, 97 (4), pp. 50-56. 
11. Fielstein, Lynda (1989). Student Priorities for Academic Advising, Do They Want a Personal Relationship. NACADA Journal 9 (1), pp. 33-38.

12. Fielstein, Lynda (1987). Student Preferences for Personal Contact in a Student/Faculty Advising Relationship. NACADA Journal, 7 (2), pp. 34-40.

13. Kelly, Karl N. and Lynch, Mary Jean (Spring 1991). Factors Students Use When Evaluating Advisors. NACADA Journal, 7 (2), pp. 34-40.

14. King, M.C. (1993). Academic Advising: Organizing \& Delivering Services for Student Success. New Direction for Community Colleges, No. 82. San Francisco: Jossey-Bass Publishers.

15. Levitz, R.S., Noel, L., and Richter, B.J. (1999). Strategic Moves from Retention Success. In Gaither, G (Ed.), Promising Practices in Recruitment, Retention \& Remediation, New Direction for Higher Education, 108 (pp. 31-49). San Francisco: Jossey-Bass Publishers.

16. Nadler, S. \& Simerly, R.(June 2006). The Effect of Listening on the Formation of Student Trust and Commitment in Academic Advising: A Study at a United States University. International Journal of Management. 23(2), pp.215-222

17. Stevenson, J., Buchanan, D., \& Sharpe, A. (2006-2007). Commentary: The Pivotal Role of the Faculty in Propelling Student Persistence and Progress towards Degree Progress. Journal of College Student Retention. 8 (2) pp. 141-148.

18. Torres, V. (2003). Student Diversity \& Academic Services. Balancing the Needs of All Students. In Kramer, G.L. \& Associates (Eds), Student Academic Services. An Integrated Approach, pp. 333-351. San Francisco: Jossey-Bass Publishers. 
NOTES 